\title{
Illness anxiety disorder and perception of disease and distress among medical students in western Saudi Arabia
}

Heba A. Ezmeirlly, MBBS, Fayssal M. Farahat, MD, PhD.

\begin{abstract}
الأهداف : تهدف هذه الدراسة الى تقدير مدى انتشار اضطراب قلق

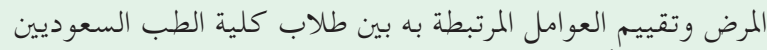

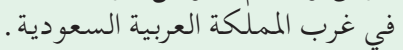

المنهجية: تم اجراء دراسة مقطعية عرضية خلال الفترة من نوفمبر

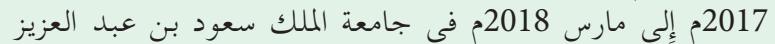

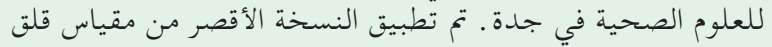

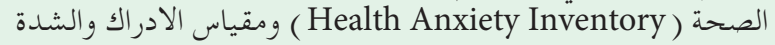
لمرض طلاب الطب من خلال التعبئة الذاتية للمقاييس.

النتائج: شارك في الدراسة عدد 271 من طلاب الطب، كان منهم

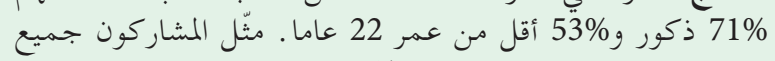
السنوات الدراسية حيث كان كان

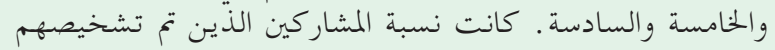

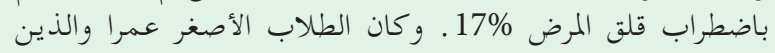

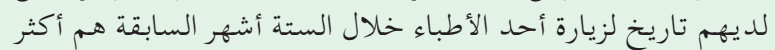

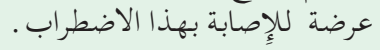

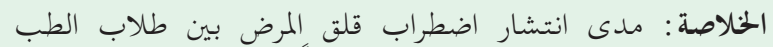

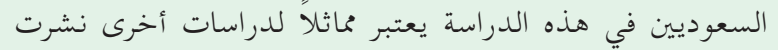

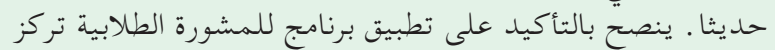

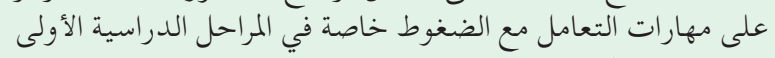

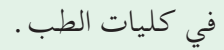

Objectives: To estimate and assess the prevalence and predictors of illness anxiety disorder among Saudi medical students in western Saudi Arabia.

Methods: A cross-sectional study was conducted from November 2017 to March 2018 at King Saud bin Abdulaziz University for Health Sciences, Jeddah, Saudi Arabia. A self-administered questionnaire was applied. The questionnaire is composed of demographic data, the short version of the Health Anxiety Inventory (SHAI), the Medical Student's Disease (MSD) perception and distress scale and history of a visit to a physician in the past 6 months.
Results: Two hundred and seventy-one Saudi medical students participated; $71 \%$ were males and $53 \%$ were less than 22 years old. The participants represented all academic years, with $54 \%$ in their 4 th, 5 th, and 6th years. Illness anxiety disorder was identified in $17 \%$ of the participants. Younger students and those with a history of a physician's visit within the past 6 months were more likely to have illness anxiety disorder $(\mathrm{OR}=2.31,95 \%$ $\mathrm{CI}=1.16,4.60 ; \mathrm{OR}=2.46,95 \% \mathrm{CI}=1.25,4.84)$.

Conclusions: The prevalence of illness anxiety disorder among Saudi medical students is comparable to similar recent studies. Student counseling programs highlighting coping techniques, especially during the early study years, should be implemented.

Saudi Med J 2019; Vol. 40 (11): 1144-1149 doi: 10.15537/smj.2019.11.24654

From the Family Medicine (Ezmeirlly), King Fahd Armed Forces Hospital; from the Infection Prevention and Control Department (Farahat), King Abdulaziz Medical City, King Saud bin Abdulaziz University for Health Sciences, King Abdullah International Medical Research Center, Jeddah, Kingdom of Saudi Arabia; and from the Department of Public Health and Community Medicine (Farahat), Menoufia University, Menoufia, Egypt.

Received 7th July 2019. Accepted 16th October 2019.

Address correspondence and reprint request to: Dr. Fayssal Farahat, Infection Prevention and Control Department, King Abdulaziz Medical City, King Saud bin Abdulaziz University for Health Sciences, King Abdullah International Medical Research Center, Jeddah, Kingdom of Saudi Arabia.E-mail: fmfayssal@gmail.com

ORCID ID: https://orcid.org/0000-0001-5186-2872

$\mathrm{I}$ llness anxiety disorder (formerly hypochondriasis) is a somatoform disorder. The affected persons suffer of prolonged fear of a serious disease that lasts for at least 6 months, and is not relieved by appropriate medical reassurance. ${ }^{1,2}$ This disorder has been reported among $18.6 \%$ of the general practice attendees in Australia ${ }^{3}$ and $5-9 \%$ of the same population in the US. ${ }^{4}$ Illness anxiety 
disorder has been referred to among medical students in earlier studies as nosophobia, hypochondriasis of medical students, ${ }^{5}$ or medical student disease. ${ }^{6}$ Medical students are more likely to develop illness anxiety disorder because of their increased probability to link symptoms and signs of serious medical conditions they are studying with their body sensations or other minor symptoms. ${ }^{7-9}$ This has been attributed to the combined effect of intensive exposure to medical and clinical knowledge and the psychological pressure caused by the study load. These factors are thought to affect symptom detection and interpretation. ${ }^{10}$ Such health concerns may interfere with students' academic performance and potentially could increase the burden on the healthcare system due to the multiple consultations and medical investigations. Previous studies showed variant proportions of hypochondriacal concerns based on the study methodology and population (range between $8.3 \%$ and $78.8 \%)^{5-7,9-11}$ Despite the increased number of medical schools, data on illness anxiety disorder (also medical student's disease or hypochondria) among medical students in Saudi Arabia are very limited. The objectives of the current study were to estimate the prevalence and factors contributing to this disorder among medical students in western Saudi Arabia.

Methods. A cross-sectional study was conducted at the College of Medicine (COM, King Saud bin Abdulaziz University for Health Sciences (KSAU-HS), Jeddah, Saudi Arabia between November 2017 and March 2018.

College of Medicine is a 6-year program for stream one (high school graduates) and 4.5 academic years for stream 2 (university graduates). Stream one students spent 2 academic years in the premedical phase compared to one academic semester for stream 2 . Both streams completed additional 2 medical academic years and 2 clinical clerkship years. ${ }^{12}$ Students of King Saud bin Abdulaziz University for Health Sciences in Jeddah during the premedical study or at College of Medicine were included. No exclusion criteria were applied. Students were approached in the study rooms or lecture theaters following regular classes.

Sample size was estimated using the following formula:

$$
\mathrm{n}=\mathrm{P}(1-\mathrm{P})\left(\mathrm{Z}_{a / 2} / \mathrm{E}\right)^{2}
$$

Disclosure. Authors have no conflict of interests, and the work was not supported or funded by any drug company.
Assuming 12\% prevalence of illness anxiety disorder among medical students (P), ${ }^{9}$ the required sample size was 254 at $4 \%$ margin of error (E), $95 \%$ confidence interval and $80 \%$ study power.

A self-administered anonymous English questionnaire was used. The questionnaire is composed of 4 sections: 1) demographic data; 2) the short version health anxiety inventory (SHAI); 3) the medical student's disease (MSD) perception and distress scale, and 4) history of a visit to a physician within the past 6 months.

The short version health anxiety inventory (SHAI) is composed of 18 items; however, only the main section (items 1-14) that measures health-related anxiety (health worry, preoccupations, and fear of illness) was applied. ${ }^{13,14}$ The SHAI is a 4-point scale ranging from 0 "not at all or rarely" to 3 "most of the time". ${ }^{13,15}$ The SHAI is considered a sensitive instrument for diagnosing health anxiety. ${ }^{15,17}$ A score of $\geq 18$ has been used and suggested by previous studies to determine significant health anxiety. ${ }^{9,16}$

The Medical Student's Disease (MSD) perception and distress scale is a 5-point scale ranging from 1 "definitely false" to 5 "definitely true". The first 5 items on the scale measure the cognitive perception component (namely, "when I experience symptoms, I try to match these symptoms to an illness I have read or heard about") and the last 5 items measure the emotional component ("I find myself worrying that I might have a disease I have just heard or read about"). ${ }^{7}$

Internal consistency (Cronbach's alpha) ranged from 0.87-0.95 for the SHAI, ${ }^{14,16}$ and 0.78-0.90 for the MSD scales $^{7,9}$ among the student population.

PubMed was used to find prior related research. Keywords used were hypochondriasis, illness anxiety and medical student disease. Ethical approval was obtained from the Institutional Review Board (IRB) of King Abdullah International Medical Research Center (KAIMRC). Participation was voluntarily and adequate, private space to complete the questionnaires on site was ensured. Confidentiality of information was assured and maintained, and no personal information or forms of identification were reported. The study was conducted according to principles of Helsinki Declaration.

Statistical analysis. Data were analyzed using IBM SPSS Statistics for Windows, version 24 (IBM Corp., Armonk, N.Y., USA). The SHAI cutoff score of $\geq 18$ was used to identify cases with illness anxiety disorder. Because of skewness in the MSD perception and distress scores, nonparametric Kruskal-Wallis and Mann-Whitney tests were applied to compare the scores according to different variables. Multivariate logistics 
regression analysis was performed to identify predictors of illness anxiety disorder. An odds ratio with a 95\% confidence interval was calculated, and the level of significance was determined to be $p<0.05$.

Results. The current study included 271 Saudi students; their mean (SD) age was 21.9 (2.6) years of age. The majority were male $(70.8 \%)$, and more than half $(53.9 \%)$ were in their 4 th, 5 th, or 6 th year. Among the studied students, $18.1 \%$ were current smokers. Four students reported antidepressant medication use. Approximately $1 / 5$ of the students (19.6\%) reported a medical condition, and $50.9 \%$ reported visiting a physician at least once during the past 6 months (Table 1). Internal consistency (Cronbach's alpha) in the current study was 0.83 for SHAI, 0.76 for the MSD perception, and 0.85 for the MSD distress scales.

Illness anxiety disorder (hypochondriasis) was identified in $17 \%$ of the participants (SHAI cutoff score: 18 or above).

Multivariate logistic regression analysis showed that the younger students were more likely to have illness anxiety disorder $(\mathrm{OR}=2.31,95 \% \mathrm{CI}=1.16,4.60$; $p=0.02$ ). The disorder was also more likely to occur in students with a history of visit to a physician in the past 6 months $(\mathrm{OR}=2.46,95 \% \mathrm{CI}=1.25,4.84 ; p=0.01)$ (Table 1).

Medical student's disease (MSD) perception and distress mean scores are reported in Table 2 .
Using non-parametric statistics (Mann-Whitney and Kruskal-Wallis tests, as appropriate), MSD distress was significantly higher among younger age students $(<22$ years old); however, none of the other studied variables showed a significant association with either the MSD perception or the distress scales (Table 2).

Perception and distress components of the MSD scale were highly correlated $\left(\mathrm{r}_{\mathrm{s}}=0.75, p=0.001\right)$, and each of them was significantly correlated with the SHAI scale $\left(r_{s}=0.57, p=0.001\right.$ and $\left.r_{s}=0.63, p=0.001\right)$; however, none of them correlated with the frequency of a visit to a physician in the past 6 months. The SHAI scores significantly correlated with the frequency of a physician visit $\left(r_{s}=0.17, p=0.01\right)$ (Table 3).

Figure 1 depicts the medical concerns of the students in response to the symptoms they reported that led them to seek medical care in the past 6 months. The number of reported concerns was 50 . The highest concern reported by one fifth of the students who visited a physician in the past 6 months (22\%) was cancer (breast, colon, leukemia, and lymphoma), followed by heart disease (8\%) (atrial fibrillation, cardiac problems related to chest pain, and hypertension), infection (bacterial, viral, and tuberculosis) (8\%), and fracture (6\%).

Discussion. The current study tackled an important, but neglected, problem that has been observed among

Table 1 - Multivariate logistic regression analysis of factors associated with illness anxiety disorder according to the health anxiety inventory score.

\begin{tabular}{|c|c|c|c|c|}
\hline \multirow[t]{2}{*}{ Variables } & \multicolumn{2}{|c|}{ Health anxiety inventory score } & \multirow{2}{*}{$\begin{array}{c}\text { Adjusted } \\
\text { odds ratio } \\
\text { (95\% confidence } \\
\text { interval) }\end{array}$} & \multirow[t]{2}{*}{$P$-value } \\
\hline & $\begin{array}{c}\text { Score }<18 \\
(\mathrm{n}=225,83.0 \%)\end{array}$ & $\begin{array}{c}\text { Score } \geq 18^{*} \\
(n=46,17.0 \%)\end{array}$ & & \\
\hline \multicolumn{5}{|l|}{ Age } \\
\hline$<22$ years $(n=143,52.8 \%)$ & $111(77.6)$ & $32(22.4)$ & $2.31(1.16,4.60)$ & 0.02 \\
\hline$\geq 22$ years $(\mathrm{n}=128,47.2 \%)$ & $114(89.1)$ & $14(10.9)$ & 1 & \\
\hline \multicolumn{5}{|l|}{ Gender } \\
\hline Male $(n=192,70.8 \%)$ & $163(84.9)$ & $29(15.1)$ & 1 & \\
\hline Female $(\mathrm{n}=79,29.2 \%)$ & $62(78.5)$ & $17(21.5)$ & $1.04(0.50,2.16)$ & 0.92 \\
\hline \multicolumn{5}{|l|}{ Study year } \\
\hline $1^{\text {st }}-2^{\text {nd }}(n=37,13.7 \%)$ & $27(73.0)$ & $10(27.0)$ & $1.24(0.47,3.24)$ & 0.67 \\
\hline $3^{\text {rd }}(\mathrm{n}=88,32.5 \%)$ & $74(84.1)$ & $14(15.9)$ & $0.63(0.28,1.42)$ & 0.26 \\
\hline $4^{\text {th }}-6^{\text {th }}(n=146,53.9 \%)$ & $124(84.9)$ & $22(15.1)$ & 1 & \\
\hline \multicolumn{5}{|l|}{ Smoking } \\
\hline Non-smoker $(\mathrm{n}=222,81.9 \%)$ & $184(81.8)$ & $38(17.1)$ & 1 & \\
\hline Current smoker ( $n=49,18.1 \%)$ & $41(83.7)$ & $8(16.3)$ & $1.22(0.51,2.92)$ & 0.66 \\
\hline \multicolumn{5}{|l|}{ Having chronic disease } \\
\hline No $(n=218,80.4 \%)$ & $185(84.9)$ & $33(15.1)$ & 1 & \\
\hline Yes $(n=53,19.6 \%)$ & $40(75.5)$ & $13(24.5)$ & $1.39(0.63,3.09)$ & 0.42 \\
\hline \multicolumn{5}{|c|}{ Visited a physician in the past 6 months } \\
\hline No $(n=133,49.1 \%)$ & $123(89.1)$ & $15(10.9)$ & 1 & \\
\hline Yes $(\mathrm{n}=138,50.9 \%)$ & $102(76.7)$ & $31(23.3)$ & $2.46(1.25,4.84)$ & 0.01 \\
\hline
\end{tabular}


Illness anxiety disorder among students ... Ezmeirlly \& Farahat

Table 2 - Mean (SD) scores of the medical student disease (MSD) perception and distress scale according to students' demographic and health characteristics.

\begin{tabular}{|c|c|c|c|c|}
\hline Variables & $\begin{array}{l}\text { MSD perception } \\
\text { Mean (SD) }\end{array}$ & $P$-value & $\begin{array}{l}\text { MSD distress } \\
\text { Mean (SD) }\end{array}$ & $P$-value \\
\hline \multicolumn{5}{|l|}{ Age } \\
\hline$<22$ years & $13.73(4.16)$ & \multirow[t]{2}{*}{0.06} & $12.53(4.82)$ & \multirow[t]{2}{*}{0.01} \\
\hline$\geq 22$ years & $12.77(4.09)$ & & $10.90(4.31)$ & \\
\hline \multicolumn{5}{|l|}{ Gender } \\
\hline Male & $13.05(4.01)$ & \multirow[t]{2}{*}{0.27} & $11.51(4.44)$ & \multirow[t]{2}{*}{0.24} \\
\hline Female & $13.85(4.44)$ & & $12.38(5.10)$ & \\
\hline \multicolumn{5}{|l|}{ Study year } \\
\hline $1^{\text {st }}-2^{\text {nd }}$ & $14.05(4.16)$ & \multirow[t]{3}{*}{0.52} & $13.03(4.57)$ & \multirow{3}{*}{0.16} \\
\hline $3^{\text {rd }}$ & $13.20(4.00)$ & & $11.77(4.67)$ & \\
\hline $4^{\text {th }}-6^{\text {th }}$ & $13.13(4.23)$ & & $11.43(4.63)$ & \\
\hline \multicolumn{5}{|l|}{ Smoking } \\
\hline Non smoker & $13.35(4.17)$ & \multirow[t]{2}{*}{0.56} & $11.84(4.66)$ & \multirow[t]{2}{*}{0.55} \\
\hline Current smoker & $12.98(4.07)$ & & $11.39(4.63)$ & \\
\hline \multicolumn{5}{|c|}{ Having chronic disease } \\
\hline No & $13.41(4.20)$ & \multirow[t]{2}{*}{0.32} & $11.77(4.69)$ & \multirow{2}{*}{1.0} \\
\hline Yes & $12.75(3.92)$ & & $11.72(4.50)$ & \\
\hline \multicolumn{5}{|c|}{$\begin{array}{l}\text { Visited a physician in the } \\
\text { past } 6 \text { months }\end{array}$} \\
\hline No & $13.11(4.36)$ & \multirow[t]{2}{*}{0.48} & $11.77(4.95)$ & \multirow[t]{2}{*}{0.79} \\
\hline Yes & $13.46(3.93)$ & & $11.75(4.32)$ & \\
\hline
\end{tabular}

Table 3 - Correlation matrix of the MSD perception and distress, SHAI and frequency of visit to a physician in the past 6 months.

\begin{tabular}{lccc}
\hline Measure & $\begin{array}{c}\text { MSD distress } \\
\text { Spearman's } \mathbf{r} \\
(\boldsymbol{p} \text {-value })\end{array}$ & $\begin{array}{c}\text { SHAI } \\
\text { Spearman's } \mathbf{r} \\
(\boldsymbol{p} \text {-value })\end{array}$ & $\begin{array}{c}\text { Frequency of visit } \\
\text { to physician } \\
\text { Spearman's } \mathbf{r} \\
(\boldsymbol{p} \text { value })\end{array}$ \\
\hline MSD perception & $0.75(0.001)$ & $0.57(0.001)$ & $0.05(0.43)$ \\
MSD distress & - & $0.63(0.001)$ & $0.08(0.22)$ \\
SHAI & - & - & $0.17(0.01)$ \\
\hline \multicolumn{2}{c}{ MSD - medical student disease, SHAI - short version Health Anxiety Inventory } \\
\hline
\end{tabular}

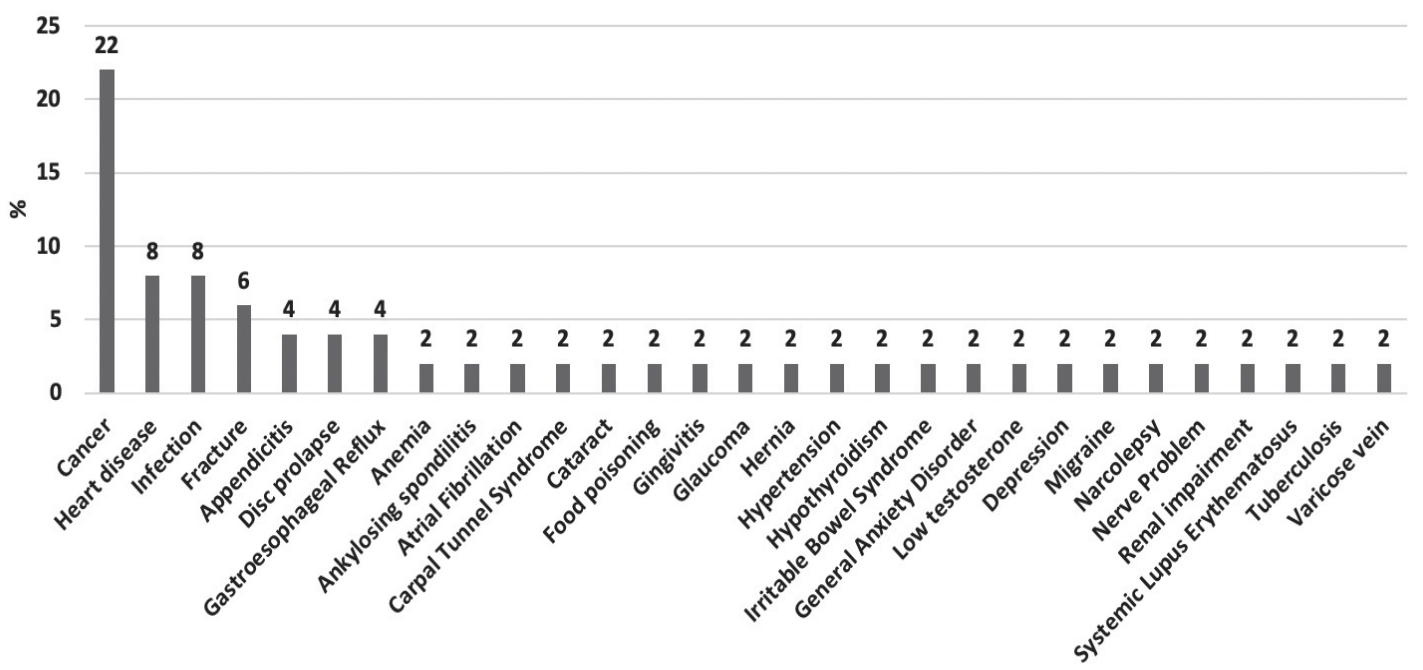

Figure 1 - Medical concerns as reported by the participants in response to the symptoms they had that led them to seek medical advice in the past 6 months. 
medical students. Illness anxiety disorder was identified in the current study in $17 \%$ of the pre-medical and medical students. The incidence was significantly higher among younger age participants and those who had a history of a visit to a physician in the past 6 months. Students during the premedical years (first 2 years at KSAU-HA) are exposed to an increased level of stress associated with the study load, and the highly competitive new environment requires higher scores as a prerequisite in order to continue to the college of medicine. Earlier studies by Hunter et al, ${ }^{5}$ Woods et $a l,{ }^{6}$ Moss-Morris and Petrie, ${ }^{7}$ Hodges,${ }^{18}$ and Collier, ${ }^{19}$ supported that medical students are at higher risk of developing health-related anxiety and hypochondriacal concerns. The current prevalence is much lower than what was reported in the earlier studies; however, it is relatively higher than the research conducted by Zahid et $\mathrm{al}^{9}$ among Pakistani medical students (11.9\%) and Kellner et $\mathrm{al}^{11}$ among American (8.3\%) medical students. Conversely, several studies $^{11,20-22}$ failed to report sufficient evidence of increased health-related anxiety among medical students compared to non-medical students. Moss-Morris and Petrie $^{7}$ explained that symptom reporting is a matter of 2 separate processes; one involves perception (cognitive) and the other involves distress (anxiety). They showed that the distress component was reduced over time. In the current study, the medical student disease distress component was significantly higher among younger age students; however, the perception component was not significant and continued without difference throughout the years. Distress was more noticeable in the early years. Meanwhile, the lack of significant association with the academic year suggests that illness anxiety disorder is more likely related to the level of stress encountered by young students. It might be mitigated by improved medical knowledge gained during advanced clinical years, as students will be more aware of the disease process and/or applicable coping mechanisms to manage the related distress. ${ }^{7,10}$

Gender was not significantly associated with increased illness anxiety disorder, MSD perception, or distress, which suggests an equal distribution of stress among both male and female participants.

Smoking in the current study was not significantly associated with illness anxiety disorder, MSD perception, or distress. This finding was contradictory to previous reports of an increased likelihood of anxiety symptoms among smokers (general public, ${ }^{23}$ young adults, ${ }^{24}$ or medical students ${ }^{9}$ ). Smoking exposure indicators, including the number of cigarettes smoked per day and the smoking index, may be considered in future studies to prove the association of smoking with anxiety. ${ }^{9}$ Kellner et $\mathrm{al}^{11}$ discussed the close contact of medical students with clinician faculty as a contributing factor to the elevated number of hypochondriacal concerns among medical students.

Fifty-percent of the students in the current study visited a physician at least once in the past 6 months. This is less than the reported percentage among Pakistani medical students $(73 \%) .{ }^{9}$ Similar to the findings of Moss-Morris and Petrie, ${ }^{7}$ the MSD perception and distress results were not significantly associated with the number of visits to doctors. Interestingly, only illness anxiety disorder revealed a positive correlation with increased visits to medical doctors. Another similar phenomenon associated with health-related internet usage (cyberchondria) was identified among university students. The likelihood of visiting a medical doctor after an internet search has been also reported. ${ }^{16}$

Physicians in the university clinics should be aware of and able to differentiate illness anxiety disorders from legitimate complaints. ${ }^{25}$ Reassurance of medical students about normal health conditions that are different from illness anxiety disorder has been documented as a valuable therapy. It may also function to differentiate and diagnose the disorder. ${ }^{9,26}$ Some previous studies emphasized the need for cognitive-behavioral therapy (CBT) and treatment interventions in collaboration with mental health clinicians. ${ }^{4,26}$

Study limitations. This study represented information from one university in western Saudi Arabia and may not be representative of other medical students. Further controlled nationwide research may provide a better understanding of the burden and contributing factors among medical and non-medical students. A personal interview may be utilized to get more in-depth information. Prospective longitudinal studies would help provide data on the health consequences of this condition and assess the related costs to the health care system.

In conclusion, $17 \%$ of the medical students studied displayed evidence of illness anxiety disorder. This prevalence is comparable to relatively recent studies among medical students and the general public; ${ }^{3,4}$ however, it is much lower compared to earlier findings that contributed to the exaggerated notion of the disorder's prevalence among medical students. ${ }^{20}$ Illness anxiety and disease distress are more likely to occur among younger age students who have an increased level of stress. This disorder was associated with more physician visits and subsequent medical investigations. The most common concerns associated with symptoms that led students to seek medical advice were cancer and heart disease. 
Student counseling programs highlighting coping techniques, especially in the earlier years of medical study, should be implemented. Nevertheless, the information is still not sufficient to concisely define the consequences of illness anxiety disorder, health-related anxiety, and distress among medical students and other trainees in medical science fields. Attention should be directed toward cyberchondria, a condition that may affect a significant proportion of the students and the general population in the current era of widespread internet use.

Acknowledgment. We would like to thank Scribendi (www. scribendi.com) for English language editing.

\section{References}

1. American Psychiatric Association (APA). Diagnostic and Statistical Manual of Mental Disorders, 5th ed. (DSM-5), American Psychiatric Association, Arlington. 2013.

2. American Psychiatric Association. Diagnostic and Statistical Manual of Mental Disorders (DSM-5). 5th ed. Washington (DC): American Psychiatric Association; 2000.

3. Clarke DM, Piterman L, Byrne CJ, Austin DW. Somatic symptoms, hypochondriasis and psychological distress: A study of somatization in Australian general practice. Med J Aust 2008; 189: $560-564$.

4. Hardy RE, Warmbrodt L, Chrisman SK. Recognizing hypochondriasis in primary care. Nurse Pract 2001; 26: 33-36.

5. Hunter RCA, Lohrenz JG, Schwartzman AE. Nosophobia and hypochondriasis in medical students. J Nerv Ment Dis 1964; 139: 147-152.

6. Woods SM, Natterson J, Silverman J. Medical students' disease: Hypochondriasis in medical education. J Med Educ 1964; 41: 785-790.

7. Moss-Morris R, Petrie KJ. Redefining medical students' disease to reduce morbidity. Med Educ 2001; 35: 724-728.

8. Ellingsen AE, Wilhelmsen I. Disease anxiety among medical students and law students. Tidsskrift for den Norske Lageforening 2002; 122: 785-787.

9. Zahid MF, Haque A, Aslam M, Aleem NA, Hussain S, Fahad $\mathrm{H}$, et al. Health-related anxiety and hypochondriacal concerns in medical students: A cross-sectional study from Pakistan. Teach Learn Med 2016; 28: 252-259.

10. Waterman LZ, Weinman JA. Medical student syndrome: Fact or fiction? A cross-sectional study. JRSM Open 2014; 5: 1-9.
11. Kellner R, Wiggins RG, Pathak D. Hypochondriacal fears and beliefs in medical and law students. Arch Gen Psychiatry 1986; 43: 487-489.

12. King Saud bin Abdulaziz University for Health Sciences (KSAU-HS): Student guide. [accessed 2019 Jan 31]. Available from: http://comj.ksau-hs.edu.sa/wp-content/ uploads/2016/08/Student-Guide-COMJ-300-01-1.0-P02.pdf.

13. Salkovskis PM, Rimes KA, Warwick HM, Clark DM. The Health Anxiety Inventory: development and validation of scales for the measurement of health anxiety and hypochondriasis. Psychol Med 2002; 32: 843-853.

14. Alberts NM, Hadjistavropoulos HD, Jones SL, Sharpe D. The Short Health Anxiety Inventory: A systematic review and metaanalysis. J Anxiety Disord 2013; 27: 68-78.

15. Lucock MP, Morley S. The health anxiety questionnaire. $\mathrm{Br} J$ Health Psychol 1996; 1: 137-150.

16. Singh K, Brown RJ. Health-related internet habits and health anxiety in university students. Anxiety Stress Coping 2014; 27: 542-554.

17. Fergus TA, Valentiner DP. The short health anxiety inventory and multidimensional inventory of hypochondriacal traits: A comparison of two self-report measures of health anxiety. Cogn Ther Res 2011; 35: 566-574.

18. Hodges B. Medical student bodies and the pedagogy of selfreflection, self-assessment and self-regulation. Journal of Curriculum Theory 2004; 20: 41-51.

19. Collier R. Imagined illnesses can cause real problems for medical students. CMAJ 2008; 178: 820.

20. Howes OD, Salkovskis PM. Health anxiety in medical students. Lancet 1998; 351: 1332.

21. Singh G, Hankins M, Weinman JA. Does medical school cause health anxiety and worry in medical students? Med Educ 2004; 38: 479-481.

22. Baric H, Trkulja V. Declining health anxiety throughout medical studies: It is mainly about a more relaxed perception of the health-related concerns. Med Teach 2012; 34: 1056-1063.

23. Mykletun A, Overland S, Aarø LE, Liabø HM, Stewart R. Smoking in relation to anxiety and depression: Evidence from a large population survey: The HUNT study. Eur Psychiatry 2008; 23: 77-84.

24. Johnson JG, Cohen P, Pine DS, Klein DF, Kasen S, Rook JS. Association between cigarette smoking and anxiety disorders during adolescence and early adulthood. JAMA 2000; 284: 2348-2351.

25. Looper KJ, Kirmayer LJ. 2002. Behavioral medicine approaches to somatoform disorders. J Consult Clin Psychol 2002; 70: 810-827.

26. Tyrer P. Recent Advances in the Understanding and Treatment of Health Anxiety. Curr Psychiatry Rep 2018; 20: 49. 